\title{
2 Gradation and degree expressions
}

This chapter of the thesis aims at providing the relevant background by discussing the notions of 'gradation' and 'degree expressions.' Section 2.1 starts with a discussion of gradation in general and of verb gradation in particular. Generally, gradation will be defined as a linguistic process of comparing degrees. Degree expressions are considered to be linguistic devices that are used to introduce a degree of comparison. Although gradation is not limited to a single syntactic class such as adjectives, it shows differences with regard to the syntactic class the graded element belongs to. In particular, verb gradation differs from grading elements of other syntactic classes since verbs are eventive. A subclassification of types of verb gradation will be discussed at the end of section 2.1.

In section 2.2, the central notion of a 'scale' is discussed in detail. Section 2.3 goes back to the notion of 'degree expressions' and starts with a short overview of different linguistic realization patterns of gradation devices. Different classifications of degree expressions will be discussed, before I turn to a deeper discussion of the cross-categorical distribution of degree expressions in section 2.4. This section starts with a discussion of Doetjes' (1997) 'degree expression continuum' which is a hypothesis about restrictions in the distribution of degree expressions. After rejecting the continuum hypothesis, a cross-linguistic comparison of the distribution of degree expression is presented. This comparison leads to the identification of different types of languages with regard to the expression of verb gradation and allows some tentative generalizations regarding the crosslinguistic distribution of degree expressions. 


\subsection{Gradation}

The aim of this first section is to clarify the notion of gradation and to indicate which phenomena are covered by this term. 'Gradation' is frequently used synonymously with 'intensification' and throughout the thesis I will use both terms interchangeably. Gradability is often considered a prototypical property of adjectives. Bhat \& Pustet (2000) state that all languages that have a distinct category of adjectives also make use of specific constructions for grading them. Bierwisch $(1989,71)$, in his discussion of gradable adjectives, uses the notion of 'gradation' as a cover term for "a range of phenomena which, for the time being, I shall call quantitative evaluations regarding dimensions of features." The phenomena Bierwisch wants to cover by his notion of 'gradation' are exemplified in (1). (1a) is a comparative construction, (b) an equative construction ${ }^{1}$, (c) exemplifies the superlative construction, in (d) we have a measure construction and in (e) a vague degree expression is used for gradation.
a. John is taller than his brother.
b. John is as tall as his brother.
c. Fohn is the tallest boy in his class.
d. John is $180 \mathrm{~cm}$ tall.
e. John is very tall.

All constructions in (1) compare the degree of John's tallness with some other degree like the degree of his brother's tallness in (a) and (b) or the degree of all boys in his class in (c). The comparative says that John's tallness exceeds the tallness of his brother, whereas the equative indicates that both - John and his brother - have the same degree of tallness. The superlative expresses that among the boys in his class, John's tallness exceeds the tallness of all others. In (d) it is the measure phrase $180 \mathrm{~cm}$ that introduces the degree to which John's height is compared. It expresses that his height is $180 \mathrm{~cm}$. In the last case, the vague degree expression very introduces an imprecise degree to which John's height is compared. The sentence in (e) states that John's height is 'high' compared to 'normally tall,' i.e. not very tall but still quite or reasonably tall people. Such a com-

See Rett (2013) and the literature cited therein for a more extensive discussion of equative constructions. 
parison, as expressed by the examples in (1), either predicates equality or inequality of degrees. The examples in (1) do not cover all types of gradation and therefore do not provide an exhaustive listing of instances that fall under the notion of 'gradation.'2 Two examples are illustrated in (2), in which the comparative is combined with a measure construction (a) and a vague degree expression (b). The examples in (2) show that the different constructions in (1) can also be combined (cf. Bierwisch 1989, 155ff. and Löbner 1990, 143ff. for a discussion of such cases in German).
a. Fohn is $10 \mathrm{~cm}$ taller than his brother.
b. Fohn is much taller than his brother.

Gradability is a semantically relevant property of adjectives as it distinguishes between adjectives such as tall which admit degree morphemes (3a) and such adjectives as dead which do not allow them (3b). As the examples show, the gradable adjective tall takes the comparative morpheme -er as well as the superlative morpheme -est in English. Nongradable adjectives normally reject degree morphemes and only admit them after some process of coercion. ${ }^{3}$ This definition is only suitable for languages that have adjectival degree morphology - which many languages lack. A more general definition of nongradable adjectives is: adjectives that cannot be used in gradation constructions without any need to coerce their meaning.
a. tall, taller, tallest
b. dead, \#deader, \#deadest

Such a general definition of nongradable adjectives can be based on the observation of Bolinger $(1967,3)$ that if an adjective admits degree adverbials such as English very it also licenses the comparative construction (cf. (4)).
a. very tall
b. \#very dead

$2 \quad$ Löbner (1990), for example, also accounts for constructions as $z u$ groß 'too tall' and groß genug 'tall enough' as basic patterns of adjectival gradation. See Morzycki (2013, 169) for a formal analysis of corresponding English examples.

3 In English, only monosyllabic and some bisyllabic adjectives take degree morphemes, whereas most polysyllabic ones use more for expressing the comparative. Hence, ungradable polysyllabic adjectives reject more without a process of coercion. 
Therefore, when I am speaking of a gradable expression throughout this thesis, I am always referring to an expression, irrespective whether it is an adjective or belongs to some other lexical category, that can be used in a gradation construction without coercing its meaning.

For adjectives, the positive form can be considered to be the basic form since it is morphologically less marked than the comparative and superlative in languages such as English, French (5) or Polish (5). In French the comparative is marked by the particle plus 'more,' whereas the adjective is uninflected for degree. The superlative also requires the definite article. Polish marks the comparative morphologically and the superlative is morphologically derived from the comparative, unlike in English where both the comparative and the superlative of monosyllabic adjectives are derived from the positive form of the adjective.

(5) French
a. grand
b. plus grand
more tall
'taller'
c. le plus grand
the more tall
'(the) tallest'

(6) Polish (Slavic $<$ Indo-European)
a. grub-y
thick-MASC.SG.NOM
'fat'
b. grub-sz-y
thick-COMP-MASC.SG.NOM
'fatter'
c. naj-grub-sz-y
SUP-thick-COMP-MASC.SG.NOM
'(the) fattest'

But there are also languages - like Mandarin Chinese (7) - in which the positive is marked compared to a comparative interpretation of gradable adjectives. A plain (gradable) adjective receives a comparative reading in 
Mandarin Chinese (7a) and the comparandum is inferred from the context (cf. Liu 2010, Grano 2012, Grano \& Kennedy 2012, Zhang 2015). ${ }^{4}$ The adjective only acquires a positive interpretation by the addition of a degree expression (7b). Li \& Thompson (1989, 143f.) state that sentences such as (7b) are ambiguous between two readings: (i) Zhangsan is tall, (ii) Zhangsan is very tall. The ambiguity arises if hěn 'very' is not heavily stressed. ${ }^{5}$

(7) Mandarin Chinese (Sinitic < Sino-Tibetian; Sybesma 1999, 27, slightly modified)
a. Zhāngsān gāo.
Zhangsan tall
'Zhangsan is taller (than someone known from context).'
b. Zhāngsān hěn gāo.
Zhangsan very tall
'Zhangsan is tall.'

The contrast between Mandarin Chinese on the one hand and the IndoEuropean languages English, French and Polish on the other hand indicates that the positive form is cross-linguistically not always the unmarked one. ${ }^{6}$ Semantically, many authors assume a similarity between the positive form and the comparative in that both express a relation between two degrees. Stating that someone is tall always requires some explicit or implicit comparison class with regard to which the respective individual is judged as tall. Taking (8) as an example, John's height has to be of quite different degree depending on the actual comparison class. If he is tall for a three-year old child, he does not - at the same time - qualify as tall for a basketball player. Thus, in the positive form, the degree of the argument of the adjec-

4 For a typological overview of the expression of comparison constructions see Stassen $(1984,1985)$ and Bobalijk (2012) for an extensive discussion of adjectival degree morphology.

5 See Chui (2000) for the claim that hěn turns into a bound morpheme in Mandarin Chinese.

6 Mauwake (New Guinea) makes use of an intensifier, in one of its comparative constructions, as a marker of a comparative rather than positive construction:

i. Poka fain maala, ne oko maala akena.

stilt this long ADD other long very

'This stilt is long but the other one is longer (lit. very long).'

(Berghäll, 2010, 272) 
tive is compared to some other degree contributed by a possibly implicit comparison class.

(8) John is tall (for a basketball player/for a three-year old child).

Authors differ as to whether they analyze the positive form as a relational expression, as Cresswell (1976) and Bierwisch (1989) do. In this case, the positive form would take two arguments, of which only one is a syntactic argument. Others, such as Löbner (1990), take the positive form as an inherently contrastive but nevertheless nonrelational construction (I will come back to this discussion in chapter 5). Irrespective of the exact analysis of the positive form, I take the positive of gradable adjectives as an instance of adjectival gradation because it expresses a relation between two degrees. The relational aspect also provides the basis for an explication of the notion of 'gradation,' for which I propose the following definition in (9):

(9) Gradation is the linguistic process of comparing two (or possibly more) degrees.

The definition of gradation is based on the notion of 'comparison,' which all the gradation constructions discussed above have in common. Since (9) is a semantic definition, I consider all constructions in which two (or more) degrees are compared as instances of gradation. This is independent of the syntactic realization of these constructions but it is also independent from the distinction between explicit comparisons (e.g. the comparative construction in English) and implicit ones (as, for example, the positive form of adjectives in English). The definition is essentially based on the notion of 'comparison' for which Bolinger $(1967,4)$ states that "comparability is a semantic feature coextensive with 'having different degrees' or 'susceptible of being laid out on a scale."' A detailed discussion of the notion of a 'scale' will be provided in chapter 2.2; for the moment it is enough to say that a scale is formed by a linearly ordered set of degrees. Something like Bolinger's characterization of 'comparability' forms the heart of current theories of gradable adjectives (Bierwisch 1989, Löbner 1990, Kennedy 1999b,a, Kennedy \& McNally 2005a among others). Gradable adjectives map their individual argument onto a scale or as Kennedy (1999b, xiii) writes: "Semantically, gradable adjectives can be informally defined as predicative expressions whose domains can be partly ordered according to 
some property that permits grading." Gradable and nongradable adjectives both induce a partial order of the objects in their domain but they do not induce the same kind of ordering (Kennedy, 1999b, xiii). An ungradable adjective as dead induces a distinction between those objects which are dead and those which are not. But there is no ranking of objects with respect to their degree of being dead. It is simply a binary contrast between 'alive' and 'dead' and it is not possible to distinguish different degrees of being dead. Gradable adjectives like tall order the objects in their domain according to a measure such as 'height' and the objects in the domain are ordered with respect to their degree of height. One can say that nongradable as well as gradable objects specify some property that functions as a basis for ordering the objects in the respective domains but they differ in that only the latter express gradable properties. ${ }^{7}$

To distinguish between gradable and nongradable adjectives, the notion of a 'gradable property' is essential. Often the notion of 'gradable property' is used without an explicit definition, as for example in Tsujimura (2001). I am aware of only two explicit definitions of this notion (Moltmann 1997; Koenig \& Chief 2008), which are both very similar. Koenig \& Chief (2008, 251) write: "[a] gradable property is a relation between an entity and a degree $d$ that obeys the following entailment pattern: For all eventualities $\mathrm{e}$, entities o, and degrees $\mathrm{d}$, if $\mathrm{e}$ is such that the property holds of o to degree $\mathrm{d}$, it also holds of o to non-zero degrees d' inferior to d." Moltmann bases her explication of 'gradable property' on the notion of 'scalar inclusion,' which is defined as in (10).

(10) For any scalar property $\mathrm{P}$, if an object $\mathrm{x}$ is $\mathrm{P}$ to a degree $\mathrm{d}$, then $\mathrm{x}$ is $P$ to the degree d', for any $\mathrm{d}^{\prime}<\mathrm{d}$.

(Moltmann, 1997, 185)

Both explications focus on the assumption that if a gradable property holds to some degree, it is entailed that it also holds to a lesser degree. This is a scalar implicature as mentioned by Koenig \& Chief and only captures a certain characteristic of gradable properties but does not define what a gradable property is. Departing from the abovementioned authors,

This does not mean that the objects in the domain of dead cannot be ordered with regard to some gradable property like 'weight' but only that dead itself does not express such a gradable property. 
I take the fact that gradable properties can hold of two individuals at the same time but allow that these individuals differ with respect to the degree of the property as their defining characteristic. An informal definition is given in (11).

(11) A property $\mathrm{P}$ is gradable if the property holds of two distinct entities $A$ and $B$ and it can truthfully be said that A's degree of $P$ is higher than B's degree of $\mathrm{P}$.

Based on the definition in (11) it can be said that an adjective is gradable, if it is possible that two individuals possess the property denoted by the adjective but differ in degree. This holds for tall as two boys can be tall but do not need to be of the same height. But it cannot be said that the degree to which Mozart is dead is higher than the degree to which Bach is dead. ${ }^{8}$

So far, the discussion has focused on gradation of adjectives but gradation is not limited to adjectives, as was mentioned quite early by Sapir (1944) and extensively discussed by Bolinger (1972). (12) shows a German example of a graded adverb:

$$
\begin{aligned}
& \text { Der funge lief sehr schnell. } \\
& \text { the boy ran very fast } \\
& \text { 'The boy ran very fast.' }
\end{aligned}
$$

Gnutzmann $(1975,421)$ argues that only adjectives and adverbs can be graded and states that "[i]n the case of nouns and verbs it is only the adjectives and adverbs associated with them which can undergo grading, not the nouns and verbs themselves." In his analysis, a grading construction such as 'what a noun' is derived from a construction as 'what an adjective noun.' In his view, it is not the noun but "some predicated quality or associated adjectival modifier" (Gnutzmann, 1975, 422) that is graded. I will not follow such a derivational approach but rather assume that nouns and verbs can be graded as such.

One reason to assume that nouns and verbs as such can be graded and that gradation does not merely affect an associate adjective is that in some languages adjectives and nouns require different degree expressions. One

I do not want to exclude coercion, which allows us to shift a normally ungradable property to a gradable property interpretation. All I want to say is that a property like 'being dead' is normally conceived as being ungradable and requires coercion for a gradable property interpretation. 
example is French, which uses très 'very' for grading adjectives (13a) and beaucoup for nouns (b). Such a difference in the choice of degree expressions would be unexpected if it were really the adjective that is graded in (b) and not the noun itself.
a. Jean est très grand.
Jean is very tall 'Jean is very tall.'
b. Jean a beaucoup faim. Jean has a lot hunger 'Jean is very hungry (lit. Jean has a lot hunger).'

In $(13 \mathrm{~b})$ the noun faim 'hunger' is used predicatively, following Doetjes $(2008,127)$, and graded by the degree expression beaucoup. Beaucoup also combines with nonpredicatively used nouns as shown in (14). Such examples are often referred to as 'adnominal quantification.' The difference between the predicatively used noun in (13b) and the nonpredicatively used nouns in (14) is that in the latter case the partitive article de is required.
a. F'ai mangé beaucoup de soupe.
$\mathrm{I}=$ have eaten a lot of.the soup
'I ate a lot of soup.'
b. Je possède beaucoup de libres.
I own a lot of.the books
'I own many books.'

Examples such as (14) seem therefore to indicate that there is no clear-cut distinction between gradation on the one hand and quantification on the other hand. I come back to this point at the end of this section, turning first to verbs and the question of how they differ regarding gradation from adjectives and nouns. With respect to verbs, two subtypes of gradation can be distinguished: extent and degree gradation. ${ }^{9}$ Extent gradation is exemplified by the English examples in (15). It is the frequency of the event that is specified by a lot in (15a), whereas a lot specifies the temporal duration of the event in (b). Both these sentences require different paraphrases. The

The distinction originally goes back to Bolinger (1972), but I use the terminology by Löbner (2012b) rather than Bolinger's original terms of 'extent' and 'inherent' intensification. 
one in (a) can be paraphrased by a sentence containing the frequency adverb often (16a), whereas sentence (b) can be paraphrased by a sentence containing an expression such as for a long time (16b).
a. He goes to the cinema a lot.
b. Last night, he slept a lot.

a. He often goes to the cinema.

b. Last night, he slept for a long time.

In the case of degree gradation, the degree expression a lot neither specifies the frequency nor the temporal duration of the eventuality. Rather, as it is the case with the stative verb in (17), a lot specifies the degree of the intensity of the feeling. An appropriate paraphrase for (17) is (18).

$$
\text { The boy hates his teacher a lot. }
$$

The boy feels a lot of hate for his teacher.

The different paraphrases for extent and degree gradation indicate that both cannot be reduced to a single type; rather, they instantiate different subtypes of verb gradation. In fact, one could argue that we have three subtypes of verb gradation: degree gradation, durative gradation and frequentative gradation. I subsume durative and frequentative gradation under the notion of 'extent gradation' and put it in opposition to degree gradation. The reason is that the split between extent and degree gradation is due to the eventivity of verbs. It is a real property of the event, i.e., its frequency or temporal duration, that is specified in the process of extent gradation, and, furthermore, non-eventive adjectives and nouns do not license an extent gradation. ${ }^{10}$ There are two further reasons to subsume durative and frequentative gradation under the label of 'extent gradation.' First, extent and degree gradation are realized in two different syntactic configurations (which will be shown in chapter 4). The two subtypes of extent gradation, on the other hand, are uniform regarding their syntactic realization (also shown in chapter 4). Second, some languages, such as German, use different degree expressions for extent and degree gradation (cf. (19) and (20))

A question which I do not raise is whether eventive nouns license extent gradation, although some clearly allow for a combination with frequency adjectives, e.g., frequent visits, a frequent update. 
but the same degree expression for both subtypes of extent gradation. ${ }^{11}$
a. Er geht viel ins Kino.
he goes much in.the cinema
'He goes to the cinema a lot.'
b. Letzte Nacht hat er viel geschlafen.
last night has he much slept
'Last night, he slept a lot.'
(20) Der Junge hasst seinen Lehrer sehr.
the boy hates his teacher very
'The boy hates his teacher a lot.'

Third, extent and degree gradation differ with regard to the source that contributes the respective gradable property. In the case of both subtypes of extent gradation, the gradable property is contributed by the eventuality, since it is a property of the event that is specified. It is either the frequency or the temporal duration of the event as such. In the case of degree gradation, it is a property of the predicate that is specified by the degree expression. 'Intensity' as the relevant gradable property in (17) and (20) is not a property of the event but of the emotion felt by the experiencer. Bosque \& Masullo (1998) argue for further subtypes of what they call 'verbal quantification.' On the one hand they distinguish between 'eventive quantification,' 'durative quantification' and 'inherent quantification'; the first two correspond to Bolinger's extent gradation and the last one to degree gradation. On the other hand, Bosque \& Masullo mention 'argument quantification' and 'unselective binder' as two further types of verbal quantification. Neither of them are covered by Bolinger's discussion of verb gradation. 'Argument quantification' is exemplified by the Spanish example in (21) in which mucho 'a lot' quantifies over an implicit or unexpressed argument of the verb. ${ }^{12}$ They mention that in case of argument quantification disagreement exists as to whether mucho functions as an adverbial or as a quantificational pronoun that features as the direct object of the verb.

\footnotetext{
11 The cross-categorical distribution of degree expression will be discussed in more detail in section 2.3

12 Cf. Bhatt \& Pancheva (2006) for an overview of different types and analyses of nonovert expressed and implicit arguments.
} 
(21) Spanish (Romance < Indo-European; Gallego \& Irurtzun 2010, 6)

a. Comí mucho (chocolate).

ate a lot chocolate

'I ate a lot (of chocolate).'

b. María leyó pocos (libros).

Maria read few books

'Maria read few (books).'

The German sentence in (22a) is similar to the Spanish one in (21a). It is stated that we ate a lot of food, without an overt realization of an argument referring to the consumed food. As (22b) shows, the sentence can also be passivized with viel figuring as the subject of the passive sentence.
a. Wir haben viel gegessen.
we have much eaten
'We ate a lot.'
b. Viel wurde (von uns) gegessen.
much was by us eaten
'A lot was eaten by us.'

The German example in (22b) can be taken as argument against an adverbial analysis of viel in constructions like those in (22a). Since viel functions as an argument of essen, I do not include cases similar to (21) and (22) in the discussion of adverbial degree gradation.

In (23), mucho is used in an unselective binder construction. The notion of 'unselective binder' goes back to Lewis (1975) and Bosque \& Masullo $(1998,30)$ mention that in such constructions mucho acts as a generic operator that binds a variable provided by indefinite noun phrases and typedenoting nominals.

(23) La gente ha leído mucho este libro. the people have read a lot this book 'People have read this book quite a lot.' (Bosque \& Masullo, 1998, 29)

Unselective binder constructions can probably be taken as an instance of extent gradation but nevertheless are a topic of their own which would require a discussion of genericity and how the generic reading of these 
examples arises. As the focus of the thesis is on degree gradation and only partly on how it is distinguished from extent gradation, I leave the topic of genericity and therefore the unselective binder construction aside.

As already mentioned above, Bosque \& Masullo consider 'degree' to be a subtype of quantification. This is also reflected in their choice of terminology, speaking of 'verbal quantification' rather than 'gradation' or 'intensification.' The authors neither explicate their notion of 'quantification' nor argue for this position. Probably the notion of 'quantification' is motivated by the fact that mucho is not only found in gradational contexts but is also used for indicating an adnominal quantity as in (24). It seems that Bosque \& Masullo extend a quantificational analysis of adnominal mucho to its adverbial use and analyze it as a quantifier in all instances.
a. mucha leche
a lot milk
'a lot of milk'
b. muchos amigos
a lot friends
'many friends'

Drawing the line between gradation and quantification is not simple, as indicated by the examples above. Several authors propose an explicit relationship between gradation and quantification. Bosque \& Masullo (1998, 22) subsume gradation under the notion of 'quantification' and write: "we crucially take degree to be a subtype of quantification." Sapir $(1944,93)$ claims that grading precedes counting and measurement. He writes (1944: 93f.) "judgments of quantity in terms of units of measure or in terms of number always presuppose, explicitly or implicitly, preliminary judgments of grading. [...] all quantifiables (terms that may be quantified) and all quantificates (terms to which notions of quantity have been applied) involve the concept of grading." Hence, grading provides the basis for quantification. Gary (1979) argues instead that 'degree' and 'quantity' are manifestations of the same category which he calls 'extent.'

Whether gradation and quantification are related depends on the notion of 'quantification.' There are two senses of quantification. In a narrow view, quantification is the expression of a relation between two predicates, a nucleus and a domain of quantification. In a broader sense, quantification 
merely means the specification of a quantity. The narrow sense of quantification is usually employed in formal semantics and represented by an approach such as Generalized Quantifier Theory (GQT, Barwise \& Cooper 1981). In the broader use of quantification, 'quantity' can be set in opposition to 'quality' and covers such dimensions as AMOUNT, NUMBER or vOLUME (cf. Eschenbach 1995, 241). Such a notion of 'quantity' does not allow distinguishing between gradation on the one hand and quantification on the other hand. This is indicated by the example in (25).

$$
\begin{aligned}
& \text { Der funge hat sehr geblutet. } \\
& \text { the boy has very bled } \\
& \text { 'The boy bled a lot.' }
\end{aligned}
$$

In (25) sehr indicates that the boy emitted a large quantity of blood. An appropriate paraphrase for (25) is (26), in which an explicit adnominal construction is used to specify the emitted quantity of blood. As these examples indicate, the notion of 'quantity' shows up in constructions which are often treated as quantificational but also in typical gradation constructions.

$$
\begin{aligned}
& \text { Der funge hat viel Blut verloren. } \\
& \text { the boy has much blood lost } \\
& \text { 'The boy has lost a lot of blood.' }
\end{aligned}
$$

There is a clear relationship between gradation and quantification in the broad sense, as specification of a quantity is nothing more than indicating a degree on a quantity scale. Quantification in the broad sense is an instance of gradation, but not the other way round, as gradation does not always consists in specifying a degree on a quantity scale. Example (27) illustrates this point, as very much cannot be interpreted as specifying the quantity but rather the intensity of love.

$$
\text { The boy loves his girlfriend very much. }
$$

In chapter 5.2.1, I show that gradation is not related to quantification in the narrow sense, meaning that degree expressions are not generalized quantifiers. In the following, I will refer to expressions such as German viel, French beaucoup or Spanish mucho as 'degree expressions' irrespective whether they specify a degree on a quantity scale or rather grade some 
quality, i.e., intensity. To focus on the adnominal use of these expressions, I will use the term 'adnominal quantity expression.' It will be shown in chapter 4 that, syntactically speaking, adnominal quantity expressions have to be conceived as quantity adjectives and I will argue in chapter 5 that they figure semantically as modifiers rather than quantifiers (in the sense of GQT).

In this section, I have shown that gradation is a phenomenon which is not restricted to a single syntactic class but can be found with adjectives, adverbs, nouns as well as verbs. I have argued for a uniform definition of gradation as a linguistic process of comparing degrees. A central component of such an analysis of gradation is the notion of a 'scale,' which is the topic of the next section.

\subsection{Scales}

In the last section, gradation was described as the process of comparing two or more degrees on a scale. Several constructions were mentioned as instances of gradation, some repeated in (28). The sentences in (28b) to (d) differ from the one in (a) in that gradation is explicitly expressed by some operator. This is the case with the comparative morpheme -er in (b), the equative as ... as in (c) and very in (d).
a. Tom is tall.
b. Tom is taller than Angela.
c. Tom is as tall as Angela.
d. Tom is very tall.

There is no explicit operator in (a) - the positive construction - used for expressing gradation. Kennedy \& McNally (2005a) argue for a morphological null positive morpheme in languages like English and German, whereas the Sinitic languages, like Mandarin and Cantonese, show an overt realization of such a morpheme. Hence, if Kennedy \& McNally are right, each gradational construction has some operator, either morphological null or explicit, expressing gradation. I will call such operators 'degree operators.'

The degree operators differ in their semantics as well as their syntax, which can be seen by the fact that the comparative licenses a comparison phrase (than Angela in (28b)), whereas the positive does not (29). 
${ }^{*}$ Tom is tall than Angela.

The last section also revealed that degree operators can take different operands. The degree operators in (28) take adjectives as operants but in the last section, we also saw examples of verbs and nouns being operants in gradational constructions. A central question is how the set of operants is restricted. Clearly, in order to be an operant in a gradational construction, a predicate needs to be gradable. Keeping the possibility of coercion in mind, the question is what it means for a predicate to be gradable. Adjectives are gradable if they denote a gradable property; but most verbs differ from adjectives in not being simple property denoting concepts. The common core for all gradable expressions is that they somehow allow access to a gradable property. Gradable properties can formally be analyzed as 'measure functions.'

Measure functions are a central ingredient in the analysis of gradable expressions, as they provide the mapping of inviduals onto scales and thereby return the degree of the individual on that scale (see below for a discussion of the notion of 'scale'). The domain of the measure function comprises individuals, whereas its range consists of degrees (Kennedy, 2007, 32). Krifka $(1990,494)$ has a somewhat more differentiated view on measure functions and writes: "[a] measure function is a function from concrete entities to abstract entities such that certain structures of the concrete entities, the empirical relations, are preserved in certain structures of the abstract entities, normally arithmetical relations. That is, measure functions are homomorphisms which preserve an empirical relation in an arithmetical relation." A measure function like 'degrees Celsius' is a mapping such that the empirical relation ' $\mathrm{x}$ is cooler than $\mathrm{y}$ ' is represented by numerical values, in this case temperature values. The structure is preserved in such a way that if $\mathrm{x}$ is cooler than $\mathrm{y}$, the numerical value of $\mathrm{x}$ is lower than the value of $\mathrm{y}$. In addition, differences are also preserved but not proportions. Krifka argues for the existence of two different types of measure functions, which he terms 'extensive' and 'non-extensive measure functions.' Extensive measure functions, like 'weight,' allow the addition of values. If $x$ weighs 6 kilograms and y weighs 3 kilograms, together they weigh 9 kilograms. Such an addition of values is not possible in case of non-extensive measure functions like 'temperature.' This is a non-extensive measure function, since if the water in a bucket has a temperature of 30 degrees and one fills in 
water that has a temperature of 40 degrees, the overall temperature of the water in the bucket does not become 70 degrees. Temperature degrees of different individuals cannot simply be added or summed-up.

The distinction between 'extensive' and 'non-extensive measure functions' is not of primary relevance in the context of verb gradation and therefore I simply use the term 'measure function' to denote any function from individuals onto degrees. Gradable adjectives and gradable verbs differ with respect to the encoding of the individual argument of their measure functions. With regard to adjectives, the argument of the measure function is the syntactic argument of the adjective. In (30a) the argument of the predicatively used adjective tall is the man, while it is also the man in case of the attributively used adjective in (b).
a. The man is tall.
b. The tall man enters the room.

In the case of verb gradation, the argument of the measure function does not necessarily coincide with one of the syntactic arguments of the verb. Take, for example, the German verb bluten 'bleed' in (31). The sentence has the interpretation that the boy is emitting a large quantity of blood. The gradable property is QUANTITY and the argument of the encoded measure function is blood not the boy since it is the quantity of blood that is measured and not the quantity of the boy.

$$
\begin{aligned}
& \text { Der funge blutet sehr. } \\
& \text { the boy bleeds very } \\
& \text { 'The boy is bleeding a lot.' }
\end{aligned}
$$

The contrast between (30) and (31) consists in the encoding of the argument that is mapped on the gradation scale. The notion of a 'scale' is crucial in the analysis of gradation and in linguistics different notions of 'scale' are used, as discussed by Westney (1986). I follow the particular approach to scales presented in Kennedy (1999b) and Kennedy \& McNally (2005a). Kennedy and Kennedy \& McNally propose a definition of 'scales' as consisting of three parameters: a set of degrees (D), a linear ordering relation $(\mathrm{R})$ - 'less than' or 'more than' - and a dimension $(\Delta)$. They write that dimensions represent the kind of measurement that is represented by the scale. Kennedy (1999b) equates dimensions with gradable properties 
but does not provide a definition of what a dimension actually is. The same holds for Schwarzschild (2006, 72), who writes that "A dimension is a kind of property like weight, volume or temperature, which can be had in varying degrees." A definition of the notion of 'dimension' is provided by Gamerschlag $(2014,277)$, based on the work of Löbner $(1979,173)$. Gamerschlag considers dimensions to represent "a space of variation which is given for a specific object property" and defines them as "a set of mutually exclusive properties of which an individual has exactly one at each point in time." A dimension, such as AGE, is a property of an object and allows for different instantiations. Different objects can be of different ages, and the age of a single objects does not need to be constant but can vary over time. A crucial fact of dimensions, in the sense of Löbner, is that they are functional and provide a unique mapping of an object onto a specific degree. This means that if AGE is a property of an object, it has some value for this dimension and also only one value at the same time.

'Dimensions' are independent from scalarity and Gamerschlag straightforwardly distinguishes between 'scalar' and 'non-scalar dimensions.' The value range of scalar dimensions is inherently linearly ordered; examples are PRICE or SIZE. An example of a non-scalar dimension is COLOR which assigns an entity a color value, but the different values, i.e., 'blue,' 'red,' 'green' and so on, are not linearly ordered (see Gärdenfors 2000). If the value range of a dimension is linearly ordered, I use the term 'degrees' to denote these values. In this view, the defining characteristic of a dimension is functionality rather than scalarity.

Kennedy \& McNally assume that all three scale parameters are explanatorily relevant. Parameter R, the ordering relation, is used in Kennedy and Kennedy \& McNally's account to distinguish between antonymous adjectives like warm and cold. These adjectives operate in the same dimension, but induce a different linear order of the temperature values (cf. Kennedy 1999b, Kennedy \& McNally 2005a). Parameter $\Delta$, the measurement dimension, is used to explain incommensurability phenomena, as indicated by the sentence in (32). The example is odd since it expresses a comparison of degrees in two different dimensions.

$$
\text { \# The girl is taller than the boy is old. }
$$


Sebastian Löbner (p.c.) mentions that it is not dimensions but scales that have to be compatible - as indicated by examples like (33a) which express a comparison in two different dimensions HEIGHT and wIDTH. Kennedy \& McNally (2005a, 352) account for examples such as (33b) by assuming that "wide and tall [...] involve orderings along a dimension of linear extent". Kennedy \& McNally lump different spatial dimensions together under the notion of 'linear extent' but Lang (1990) presents arguments for a distinct representation of the different spatial dimension encoded in language. I agree with Löbner's comment and do not assume that the incommensurability can be reduced to a fit of dimension. But I do not discuss this topic further as it is not central to my topic.
a. The chair is higher than the table is broad.
b. They call him 'The Bus' because he's kind of as wide as he is tall. (Kennedy \& McNally, 2005a, 352)

The parameter $\mathrm{D}$ - the set of degrees - specifies whether a minimal and/or maximal scale value exists (e.g. Kennedy \& McNally 2005a, Kennedy 2007, 32). A maximal scale value is the highest degree, so that no higher degree exists. The reverse holds for minimal scale values. The presence vs. absence of minimal and maximal scale values determines one of the formal characteristics of scales, namely whether they are (partially) closed or open. With respect to the presence vs. absence of maximal/minimal scale values four types of scales are distinguished: (i) a scale can have a minimal and a maximal scale value, then it is closed; (ii) a scale can have a minimal but no maximal scale value, then it is closed at the lower end, (iii) a scale can have a maximal but no minimal scale value, then it is an upper closed scale, and (iv) a scale can have neither a minimal nor a maximal scale value. In this case it is an open scale. These distinctions result in the scale typology summarized in (34).

$$
\begin{array}{ll}
\text { a. } & \left\langle\mathrm{D}_{[0,1]}, \mathrm{R}, \Delta\right\rangle=\text { (totally) closed scale } \\
\text { b. } & \left\langle\mathrm{D}_{[0,1)}, \mathrm{R}, \Delta\right\rangle=\text { lower closed scale } \\
\text { c. } & \left\langle\mathrm{D}_{(0,1]}, \mathrm{R}, \Delta\right\rangle=\text { upper closed scale } \\
\text { d. } & \left\langle\mathrm{D}_{(0,1)}, \mathrm{R}, \Delta\right\rangle=\text { open scale }
\end{array}
$$

(Kennedy \& McNally, 2005a, 354) 
Kennedy and Kennedy \& McNally assume that degrees can be considered as isomorphic to the real numbers between 0 and 1 . The interval of real numbers is marked as a subscript to parameter D. Round and square brackets are used to indicate whether the interval includes 0 and 1 (in this case, the scale is closed at the respective end) or only approximates 0 and 1 . As there is "no smallest non-zero between 0 and 1, and no largest non-one number either" (Morzycki 2013, 126) the scale is an open interval. Kennedy \& McNally do not assume that degrees actually are real numbers or that all dimensions are associated with numerical degrees. The assumption that degrees are isomorphic to real numbers is merely a way of formalizing degrees. I will not go on to discuss the question whether this assumption is necessary or probably even too strong since nothing in my analysis hinges on this assumption.

The structure of the scales, whether they are (partially) closed or open, is reflected by different linguistic asymmetries. The endpoint modifier is completely oriented toward an endpoint of a scale, irrespective whether it is a minimal or a maximal one. As can be seen in (35), the two antonymous adjectives empty and full can both be combined with completely, which indicates that the scale measuring 'fullness' is closed at both ends. This coincides with the intuition that if something is full or empty it cannot get fuller or emptier. Hence, the compatibility of an expression with completely can be taken as evidence for the presence of a maximal, resp. minimal scale value and therefore for a (partially) closed scale.

a. The bucket is completely empty.

b. The bucket is completely full.

Proportional modifiers like half and halfway require totally closed scales, since the determination of a mid-value requires a beginning and an end point (cf. Kennedy \& McNally 2005a, Bochnak 2013b). Therefore, the compatibility with half indicates a totally closed scale, as is the case with full in (36).

The bucket is half full.

Open scale predications reject the combination with endpoint modifiers as well as proportional modifiers. Intuitively, adjectives such as expensive and tall are related to open scales, since one always can think of an increase 
in price or some higher 'height.' Linguistically this is reflected by the fact that the combination of expensive/tall with completely/half results in odd sentences (37). Lexically, there is no upper or lower bound specified by these adjectives.
a. \#The book is completely expensive.
b. \#The book is half expensive.
c. \#The tower is completely tall.
d. \#The tower is half tall.

Also adjectives that are related to closed-scale predications are gradable. This is shown by the fact that they admit comparative constructions (38), which require some coercion with ungradable adjectives like nuclear or extinct (39). The difference between nuclear and extinct on the one hand and full and visible on the other hand is that the latter denote a gradable property while the former do not. Full is related to a scale of 'fullness' and denotes, following the argumentation presented above, the maximal degree on that scale.
a. The glass isn't as full as I would like it to be.
b. The sign for the Main Street exit is less visible than the one for the Spruce Street exit.

(Kennedy \& McNally, 2005a, 356)
a. ??The energy we use these days is more nuclear than it was before they build that plant down the road.
b. ??Dinosaurs are more extinct than spotted owls.

(Kennedy \& McNally, 2005a, 356)

Above, I mentioned that endpoint-oriented adjectives denote the maximal scale value, but that statement is too simplistic. As Ropertz (2001) as well as Kennedy \& McNally show, some endpoint-oriented adjectives also have non-endpoint-oriented uses (Kennedy \& McNally 2005a, 357 call them 'imprecise uses'). A sentence such as (40a) does not necessarily mean that the glass is completely full and nothing more could be filled in. For example, a drinking glass in a restaurant is normally not filled up to the brim but nevertheless a sentence such as (40a) would be true of the drinking glass, even if more liquid could be filled in. Kennedy \& McNally also mention the 
example in (40b), which shows that something can be described as full, but at the same time is not necessarily completely full.


(Kennedy \& McNally, 2005a, 357)

One closed-scale adjective which does not allow an 'imprecise use,' or at least not as easily as English full does, is German unsichtbar 'invisible.' Unsichtbar expresses a zero degree of 'visibility' and a sentence like (41) is rather odd.

(41) \#Der Mann ist unsichtbar, aber er könnte noch unischtbar-er sein. the man is invisible but he could still invisible-сомp be 'The man is invisible but he could be even more invisible.'

'Imprecise uses' of full and other closed-scale adjectives can either be seen as an instance of coercion or rather as exemplifying the fact that they do not denote a single value on the scale, i.e., the scale's maximal degree, but rather a range of values. This range of values can be taken as an extended endpoint; it consists of the endpoint and a set of degrees preceding the endpoint. I use the term 'end range,' in opposition to 'endpoint' for such an extended endpoint. An 'end range' has a lower and an upper bound. The upper bound is the maximal scale value, whereas the lower bound is context-dependent. We have different standards for judging a glass as 'full, but not completely full' opposed to judging a theater as 'full, but not completely full.' 'End range'-adjectives, unlike strict endpoint adjectives, are compatible with endpoint expressions like completely but also allow for 'imprecise uses.' The notion of an 'end range' will figure crucially in the analysis of gradable telic change of state verbs in chapter 6 .

Closed-scale as well as open-scale adjectives require an evaluation standard that is referred to as 'comparison class.' The notion of a 'comparison class' has to be set apart from the notion of a 'standard.' A comparison class specifies a contextually relevant subset of the domain of the gradable predicate. If one says that John is tall for a basketball player, then the comparison class restricts the domain of the adjective to those entities who are basketball players. John's tallness is not compared to the tallness of all 
individuals in the adjective's domain, which would be all individuals that have some degree of height. As (42) shows, the comparison class can be overtly specified, but it can also be left implicit.
a. This is expensive for a book.
b. This is expensive for a car.

A standard can be defined, following Kennedy (1999b, 9), as "a value that provides a means of separating those objects for which the statement $\mathrm{x}$ is $\varphi[\varphi$ being a gradable predicate $]$ is true from those objects for which $\mathrm{x}$ is $\varphi$ is false, in some context." Morzycki $(2013,108)$ describes a standard as "the smallest degree on a scale consistent with satisfying the predicate - that is, the cut-off point that divides, say, the tall from the non-tall." The standard is the actual value (it can be rather imprecise and does not need to be a concrete degree) that induces a separation within the comparison class between those individuals for which the respective predication is true and those for which it is not. Clearly, the standard is dependent on the comparison class. If I am saying that someone is tall, the respective standard is different depending on the chosen comparison class. The standard is a higher degree if I compare John's tallness with those of basketball players than if I compare it with three-year-old children. Furthermore, Kennedy \& McNally (2005a) propose that a relationship between the type of scale (open vs. closed) and the nature of the evaluation standard exists. They distinguish between two types of standards, which they call 'relative' and 'absolute standard.' A relative standard is context-dependent as in the examples in (42). In (a) the actual price could be 50 euros, which would be expensive for an ordinary book, whereas in (b) the price has to be clearly higher, probably more than 30,000 euros. Whether the price of the referent of this is conceived as expensive or not depends on the comparison class. Adjectives related to relative standards are called 'relative adjectives' by Kennedy \& McNally (2005a). Absolute standards are not context-dependent but fall together with an endpoint of the scale. An adjective such as full in (43) can be evaluated with regard to its absolute standard. This does not require a comparison class, as a sentence like (43) does not mean that the Honda is full compared to a van in general. Rather in the endpoint oriented reading full means that nothing more could be put into the Honda independent of any comparison class. 

The Honda is full.

Absolute standards default to a scale endpoint and, in the case of closedscale adjectives, they either fall together with the minimal or the maximal scale value. Kennedy \& McNally (2005a) call adjectives related to absolute standards 'absolute adjectives.' ${ }^{\text {13 }}$

Open-scale adjectives cannot be related to absolute standards since they lack such endpoints. As mentioned above, full is an 'end range' rather than 'endpoint' adjective and therefore also allows an evaluation with respect to a context-dependent standard which marks the lower bound of the 'end range.' The presence of two standards explains the different reading of full discussed above. Standards do not have to be proposed as an additional scale component, but result from the structure of the scale (open vs. closed). A more fine-grained distinction of types of (relative) standards is provided by Leisi (1971). He does not use the term 'standard' but instead speaks of 'norm.' In the following, I will use the terms 'standard' and 'norm' interchangeably. Leisi distinguishes between the following three types of norms: 'species norm,' 'appropriateness norm' and 'individual expectation norm.' A species norm is a standard value determined by a prototypical proponent of a certain species. Example (44) indicates this kind of norm, since the standard value is determined by the height of prototypical basketball players. In this case, the nominal phrase basketball players represents a 'species' of individuals.

The guy is tall for a basketball player.

An appropriateness norm is context-dependent, like the other norms too. Unlike the species norm, it is not a prototypical member of a species that determines the standard but the appropriateness of the referent of the argument with regard to some goal. For example, someone can be judged as tall with respect to some species but, at the same time, he can be small with regard to some goal. So he can be described as small if he has to change a bulb and is not able to reach it. The last type of norm - individual expectation norm - is based on the speaker's expectations. If, for example, I have not seen my nephew for a while and expect him to have grown quite a lot

$13 \quad$ Yoon (1996) and Rotstein \& Winter (2004) are speaking of 'partial' and 'total adjectives' rather than absolute and relative ones. 
and realize that he hasn't, the sentence in (45) is based on my expectation of his size, resp. change of size. In such a case, I am not comparing him to other children of his age, so the individual expectation norm is not the same than the species norm.

\section{He is still small.}

As the examples have shown, species norm, appropriateness norm and individual expectation norm are subtypes of relative standards. Leisi's norms provide a more fine-grained subdivision of what Kennedy \& McNally call a relative standard. In the remainder, I will speak only of relative standards and leave open what subtype of relative standard is actually invoked.

Kennedy \& McNally's scale typology is only based on the presence vs. absence of maximal/minimal scale values. A different scale typology is proposed in measurement theory and formulated by Stevens (1946). He distinguishes between nominal, ordinal, interval and ratio scales. Nominal scales do not presuppose a linear order, but only allow for determination of equality or inequality. Nominal scales are enough to express a comparison, which is only concerned with a judgment of inequality/equality. But Kennedy \& McNally's definition of scales requires a linear order on the set of degrees. Therefore, scales in the sense of Kennedy \& McNally cannot be nominal scales. Rather they have to be at least ordinal scales of which school grades are an example. Like interval and ration scales, ordinal scales induce a linear order, but these three types of scales differ in their formal properties. Interval scales, in contrast to ordinal scales, allow the determination of an interval between two distinct degrees. Therefore, a difference between any two arbitrary degrees can be calculated. An example for a scale of such a type is temperature on the Celsius scale. Ratio scales, which have the same properties as interval scales, also allow multiplication and addition of degrees and have a meaningful zero point. Temperature on the Kelvin scale is measured on a ratio scale. Sassoon (2010) argues that the distinction between ordinal, interval and ratio scales is not merely mathematically but also linguistically relevant. But there is very little reflection of that type of scale typology in the semantics literature; exceptions are Wiese (1997) and Sassoon (2010). However, the analysis of verb gradation this scale typology does not seem to be of greater relevance, and therefore it will play no further role in the following analysis. 


\subsection{Degree expressions}

The notion of a 'degree expression' is closely related to the notion of 'gradation' as degree expressions are devices used for gradation. The function of a degree expression is to specify the comparison degree to which the argument of gradable property is compared. As will be made clear during the latter parts of the thesis, specification of a comparison degree can consist either in introducing such a degree, for example, in case of the positive null morpheme, or in, for example, specifying a difference between the two degrees compared. At this stage, I use the term 'degree expression' for devices used for gradation rather than 'intensifiers.' The reason is that intensifiers form a certain subtype of degree expressions which will be formally distinguished from other subtypes of degree expressions in chapter 5. In the current section, I aim at a general discussion of gradation devices and therefore speak of degree expressions in general.

Gradation can be expressed by different morphosyntactic means. Following Bhat \& Pustet $(2000,759)$, we have two different morphosyntactic types of adjectival degree constructions in (46a) to (e), which are repeated from chapter 2.1. The examples in (a) and (c) show a morphological expression of gradation, by suffixing the degree morphemes -er and -est to the adjective. Examples (b), (d) and (e) are characterized as syntactic ways of expressing gradation. Each non-morphological way of expressing gradation is considered by Bhat $\&$ Pustet to be a syntactic construction. ${ }^{14}$
a. Fohn is taller than his brother.
b. John is as tall as his brother.
c. John is the tallest boy in his class.
d. Fohn is $180 \mathrm{~cm}$ tall.
e. John is very tall.

Languages differ with respect to the morphosyntactic realization of gradation constructions. An extensive discussion of this point can be found in Stassen (1985) with regard to the comparative construction (also cf. Bhat \& Pustet 2000, 759). Beside explicit degree morphology, as in the English

Bhat \& Pustet (2000) do not mention phonological devices for gradation, as for example prosody (cf. Bolinger 1972, chapter 15) or phonological lengthening (cf. Bolinger 1967, 4). 
cases in (46a) and (c), reduplication is another often used morphological way of expressing gradation. (47) shows an example from Basque, in which an adjective is reduplicated to intensify its meaning. Moravcsik (1978) mentions that reduplication is also used for expressing iterativity (48)/(49), which is similar to verbal extent gradation (also Moravcsik 2013, 129f.). ${ }^{15}$

(47) Basque (Isolate; Bhat \& Pustet 2000, 759)

zopa bero-bero dago

soup hot-hot is

'The soup is very hot.'

(48) Tzeltal (Mayan; Moravcsik 1978, 318)

-pik -pikpik

'touch it lightly' 'touch it lightly repeatedly'

(49) Sundanese (Austronesian; Moravcsik 1978, 318)

guyon guguyon

'to jest' 'to jest repeatedly'

German does not have productive reduplication, but a repetition of words can be used to express intensification. The example in (50) allows for an interative or durative interpretation and hence represents an instance of extent gradation.

(50) Er hat gelogen, gelogen, gelogen.

he has lied lied lied

'He lied, lied, lied.'

(van Os 1989, 111)

Degree morphology is not restricted to adjectives and the expression of comparative and superlative constructions. ${ }^{16}$ Jalonke, for example, does not have a separate class of adjectives rather what is expressed as adjectives in German or English is realized as a verb in Jalonke. The distributive morpheme $m a$ - is used in Jalonke for degree gradation (51) as well as extent gradation (52), expressing iteration. Note that the prefix $m a$-in Jalonke

$15 \quad$ Reduplication is not exclusively used for gradation but serves many other semantic functions as shown in Moravcsik (1978).

16 See Wellwood et al. (2012) for a discussion of nominal and verbal comparative constructions. 
specifies a low degree with adjectival concepts but a high degree if used as specifying the extent.

(51) Jalonke (Mande < Niger-Congo; Lüpke 2005, 308)

a. bundaa ma-bundaa

'be wet' 'be a little wet'

b. fisa ma-fisa

'be better' 'be a little better'

(52) Nxo ma-giri xure-n' $i$.

1.PL.E DISTR-cross stream-def at

'We crossed the stream a lot.'

(Lüpke, 2005, 309)

Syntactic devices used for gradation are free morphemes that are used for expressing gradation. In languages such as English or German, such expressions are realized as adjectives or adverbs. (53) shows the gradational function of some adjectives in English; the operants of gradation are nouns (also see the literature mentioned in Morzycki $(2013,245)$ on nominal gradability).

The adjectives enormous, big and huge function as degree expressions in (53), taken from Morzycki $(2009,176)$, hence they function as degree operators. Commonly, they are used as operands of gradation, as they are plain gradable adjectives. The difference between use as degree operator and that of being an operant of gradation can be exemplified by (53b). Big expresses that some individual is large in seize but in (53b) the sentence does not express that Gladys is big or that she is big and a stamp collector. Rather big intensifies stamp collector and has the interpretation that Gladys is very 'into' collecting stamps.

a. George is an enormous idiot.

b. Gladys is a big stamp collector.

c. Three huge goat-cheese enthusiasts were arguing in the corner.

Gary $(1979,46)$ states that "[a]lmost any adjective or adverb that connotes some sense of extremity can serve a degree modification function." ${ }^{17}$

17 Cf. Edel (1992) for an overview of devices for gradation of nouns in Russian and Bulgarian. 
Kirschbaum (2002) presents an extensive analysis of adjectival intensification and demonstrates how productively different kinds of expressions can be used as degree expressions. Expressions such as big and huge on the one hand differ from such expressions as much, very, viel or sehr in that the latter are restricted to being degree operators whereas the former function as degree operator only in certains uses. A crucial difference between degree expressions like German sehr and adjectives such as laut 'loud' is that the latter lexically specify a scale, whereas the former do not. In (54), the adverbially used adjective laut is combined with a verb of sound emission in (a) and with an action verb in (b). Irrespective of the verb, laut indicates a high degree on a Loudness scale. This is different for sehr, as the scale is dependent on the semantic class of the graded verb. The examples in (55) can be used for illustration. With respect to weinen 'cry,' sehr specifies the INTENSITY, i.e., the LOUDNESS, of the emitted sound. But with a verb like bluten 'bleed' it is the QUANTITY of the emitted substance and not the INTENSITY that is specified by sehr.
a. Das Kind weint laut. the child cries loud 'The child is crying loudly'
b. Das Kind hämmert laut. the child hammers loud 'The child is hammering loudly.'
a. Das Kind weint sehr. the child cries very 'The child is crying loudly.'
b. Das Kind blutet sehr. the child bleeds very 'The child is bleeding profusely.'

Sehr and other degree expressions do not lexically encode a scale and are compatible with different types of scales such as INTENSITY and QUANTITY. Hence, the degree expressions require that the graded predicate provides a suitable gradation scale. Laut is restricted to the LouDNEss scale as it lexically encodes this scale. Therefore, the adjective does not require a predicate that provides a loudness scale but only one which is compatible with its own predication. In the remainder, I restrict myself to lexical ex- 
pressions that only serve as degree expressions and thereby exclude such cases as in (54) which do not show such a restriction.

Bhat \& Pustet $(2000,759)$ note that languages sometimes correlate degree modification with other functions such as plurality marking of nouns. The authors mention the case of Obolo, which uses the verbal affix $m i$-for marking plurality of the subject (56a) if the verb is in the past or completive indicative (Faraclas, 1984, 10). Example (56b) shows that $m i$ - is ambiguous between indicating a plurality of the subject and intensifying the predicate.

Obolo (Niger-Congo; Faraclas 1984, 10f.)
a. Ėmâ míbàbíge íkpá.
1PL MI.write.comp book
'They wrote the book (already).'
b. ikpá mîjàán
book MI.be.beautiful
'The books are good.' or 'The book is very good.'

The examples from Obolo raise the question whether plurality can in general be taken as an instance of gradation. ${ }^{18}$ This question goes beyond the limits of the current thesis but surely the data indicate that the expression of quantity is deeply connected to gradation. This has already been indicated in section 2.1 and will be shown in more detail in section 2.4.2. As a consequence, I consider expressions used for the specifying quantity, such as English much and German viel in their adnominal uses, to be degree expressions.

Degree expressions can be classified based on "the region of the scale that they occupy" (Bolinger, 1972, 17). Degree expressions differ with respect to the degree they induce, which means that they lead to different partitions of a scale. Several authors, such as Biedermann (1969), Bolinger (1972) and van Os (1989), assume that a fixed set of regions of a scale can be identified and that each degree expression introduces a degree falling in one of these regions. The authors differ with regard to the exact number of scale regions they distinguish and also with regard to the question whether 'negative' should also be considered as a scale region or not. An affirmative answer to this question implies that negation expressions would also have to be

$\overline{18}$ See Cresswell (1976) for a degree-based analysis of plurality. 
considered to be degree expressions. Biedermann assumes 'negative' to be a scale region, whereas Van Os argues that English not is not a degree expression. ${ }^{19}$ Instead he proposes the seven scale regions listed in table 1, which are illustrated with examples from German (following Kirschbaum 2002, 43).

(i) absolute völlig 'absolutely,' ganz 'completely'

(ii) approximate fast 'almost,' beinahe 'nearly'

(iii) extremely high höchst 'highly,' furchtbar 'terribly'

(iv) high

(v) moderate sehr 'very', besonders 'notably'

(vi) weak

(vii) minimal ziemlich 'rather', relativ 'relative' etwas 'slightly,' ein bisschen 'a bit' wenig 'little,' kaum 'rarely'

Table 1: Classification of degree expressions.

The classification of degree expressions in table 1 is based on Horn's (1969) suspension test. With respect to degree expressions, the idea of this test is that a degree expression $A$ indicates a higher degree than degree expression $B$, if it is possible to say something is $B$, if not $A$. Degree expression $B$ is weaker than degree expression $A$, if the suspension test does not lead to a contradiction. The test construction leads to a contradiction if A indicates a lower degree than B. Crucial for this test is the notion of 'scalar implicature,' which means that certain lexical expressions entail a lower bound, in case of degree expressions the standard introduced by them, but only conventionally implicate an upper bound (cf. Horn 1989, 1998 on scalar implicatures). The contradiction arises in cases in which A indicates a degree that falls below the entailed lower bound of $\mathrm{B}$. Since the upper bound is merely an implicature, it can be suspended. (57) and (58) illustrate this test for the German degree expressions etwas 'slightly,' sehr 'very' and höchst 'highly.'20

\footnotetext{
19 I do not take a stance on the question whether not and similar expressions are degree expressions or not.

20 Cf. Gary (1979, 9ff., 97ff.) for a classification of English degree expression based on the suspension test.
} 
a. Sein Zustand hat sich etwas verbessert, wenn nicht sogar his condition has REFL slightly improved if not even sehr.

very

'His condition has improved slightly, if not significantly'.

b. \#Sein Zustand hat sich sehr verbessert, wenn nicht sogar

his condition has refl very improved if not even etwas.

slightly

(58) a. Er war sehr, wenn nicht sogar höchst erfreut.

he was very if not even highly pleased

'He was very, if not extremely pleased.'

b. ??Er war höchst, wenn nicht sogar sehr erfreut.

he was highly if not even very pleased

In the case of endpoint expressions such as German völlig and ganz, which are classified as 'absolute' by van Os and Kirschbaum, a suspension of the implicated upper bound is not possible. This is due to the fact that in such cases the entailed lower bound and the implicated upper bound fall together. An essential point that has to be kept in mind is that 'absolute' degree expressions and approximaters only apply to closed-scale predicates, and whereas it is assumed for other degree expressions, such as English very, that they require an open-scale predicate (cf. Kennedy \& McNally 2005a). Due to scale incompatibility, not all degree expressions can be contrasted in the suspension test. Ignoring those degree expressions that require closed scales, the strength of degree expressions can be arranged as illustrated in figure 1. Canonically, open scales are represented by an arrow and degrees increase from left to right. Figure 1 shows the subdivision of a scale into five different regions, which is based on the suspension test. The boundaries of the regions do not correspond to fixed degrees but are context-dependent.

Abeillé et al. (2004) present a classification of different types of adverbs which focuses on those used for the expression of extent and degree gradation. The authors base their classification on previous work by de Swart (1993) and Doetjes (1997) and argue for a distinction between, on the one hand, adverbs of quantification and on the other hand, degree 


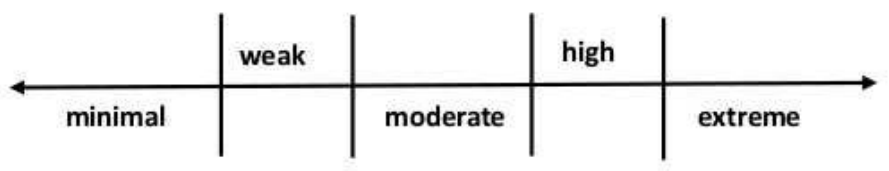

Figure 1: Scale partitioning induced by lexical degree expression.

adverbs. Adverbs of quantification consist of two subclasses: frequency adverbs such as often and seldom and iterative adverbs like two times. The function of these adverbs is counting events. ${ }^{21}$ Degree adverbs are subdivided into three classes: degree quantifiers, intensity adverbs and adverbs of completion. Adverbs of completion are expressions like completely, which are oriented towards an endpoint of a scale. Intensity adverbs, like German sehr, indicate a degree on a scale and are, following Abeille et al., restricted to degree gradation of adjectives and verbs. The last class of degree adverbs is called 'degree quantifiers.' An example of a degree quantifier is French beaucoup 'a lot' and such adverbs can have "a quantificational-like interpretation" (Abeillé et al., 2004, 196). The quantificational-like interpretation can be observed in examples like (59b), in which beaucoup is near synonymous with souvent 'often' (a). But in contrast to souvent, beaucoup can be used for indicating a degree, therefore it is not classified as an adverb of quantification, rather it seems to be in between intensity adverbs and adverbs of quantification. Abeille et al.'s partial classification of adverbs is summarized in figure 2 .
a. Jean va souvent au cinéma.
Jean goes often to.the cinema
'Jean often goes to the movies.'
b. Jean va beaucoup au cinéma.
Jean goes a lot to.the cinema
'Jean goes to the movies a lot.'

There are some problems that show up with the classification in figure 2. First, the term 'degree quantifier' is (at least) confusing, since it seems to indicate that expressions such as beaucoup are ambiguous between a quantificational and an intensifying function. Second, the classification

1 I will discuss the question, whether 'adverbs of quantification' are quantifiers, in the sense of 'Generalized Quantifier Theory' in chapter 5. 


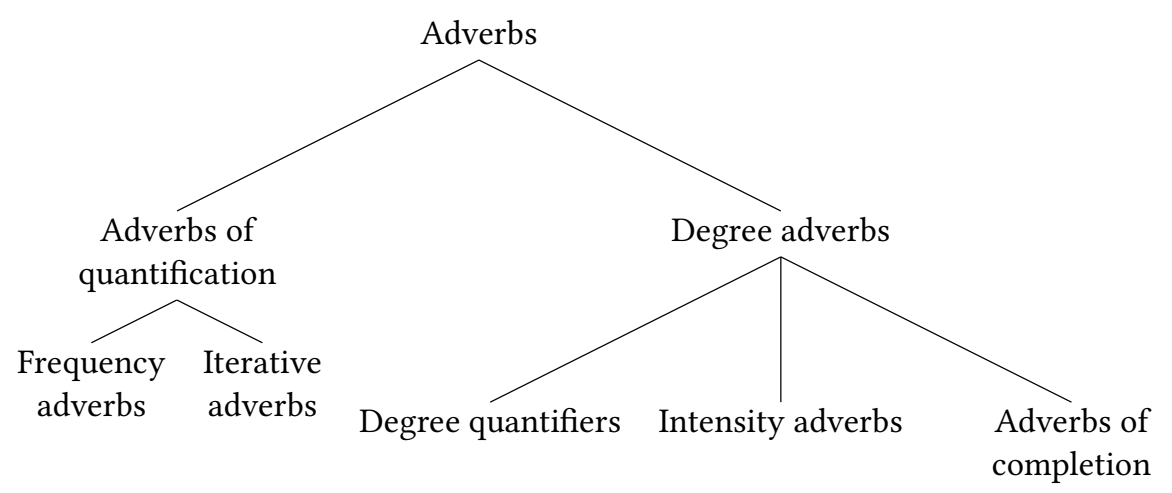

Figure 2: Partial classification of adverbs (Abeillé et al., 2004).

does not really capture degree expressions such as German viel, which can be used in sentences like (60), which is the German equivalent of (59b). But unlike beaucoup, viel is not used for expressing degree gradation of verbs. So it is not clear to me whether Abeille et al. would classify viel as a degree quantifier, as an adverb of quantification, or if they would have to make up a fourth category of degree adverbs.

(60) Peter geht viel ins Kino.

Peter goes much in.the cinema

'Peter goes to the movies a lot.'

Instead of relying on Abeille et al.'s classification of degree adverbs, in the next section I will provide a different classification based on the crosscategorical and cross-linguistic distribution of degree expressions. Before I turn to the cross-categorical disctribution of degree expressions, a note on the use of the notion 'degree adverb' is required. I do not analyse viel and sehr as adverbs, rather they are adjectives. In the context of verb gradation, these adjectives are used adverbially. Hence, I am speaking of 'degree adverbials' instead of 'degree adverbs' and focus on the function of the expression rather than on its lexical category. One argument in favor of an analysis of viel and sehr as adjectives is that they have suppletive comparative and superlative forms like other adjctives do. Both sehr and viel share their comparative and superlative forms which are mehr 'more' and am meisten 'most' respectively. 


\subsection{Cross-categorical distribution of degree expressions}

In this section, I discuss the cross-categorical distribution of degree expressions. In 2.4.1, I start with Doetjes' 'degree expression continuum,' which is intended to describe the cross-categorical distribution of degree expressions and provides a constraint on their distribution. Section 2.4.2 compares the distribution of degree expressions from a cross-linguistic perspective.

\subsubsection{Degree expression continuum}

In her work on French, Dutch and English degree expressions, Doetjes (2008) mentions that degree expressions differ with regard to their crosscategorical distribution. Depending on their cross-categorical distribution, she identifies different types of degree expressions. I will not focus on the types of degree expressions she distinguishes, but on her general claim that degree expressions form a continuum and that the continuum constrains their distribution. An essential part of her analysis is the claim that degree expressions can only apply to adjacent contexts in the degree expressions continuum.

Doetjes distinguishes the following six contexts in which degree expressions can be used: (i) gradable adjectives, (ii) gradable nominal predicates, (iii) gradable verbs, (iv) eventive verbs, eventive adjectives, comparatives, (v) mass nouns, and (vi) plural nouns. I illustrate these contexts below by taking French (très and beaucoup) and German high degree expressions (sehr and viel) as examples. I will show parallel examples from French in (a) and German in (b).

The first context is the combination of a gradable adjective with a degree expression. This is the only context in French in which très is used. ${ }^{22}$ German uses sehr with gradable adjectives. The other mentioned degree expressions, beaucoup in French and viel in German, cannot be used in this context.

22 Cf. Doetjes (2008) for a case study of très and examples in which it (nonsystematically) extends to other degree contexts. 

a. Paul est très grand.
Paul is very tall
'Paul is very tall.'
b. Paul ist sehr groß.
Paul is very tall
'Paul is very tall.'

The second context comprises gradable nominal predicates, i.e. predicatively used nominals as in (62). French uses beaucoup for grading such nouns and German makes use of viel. This is not unexpected since beaucoup as well as viel also function as adnominal quantity expressions in French and German.
a. Jean a beaucoup faim.
Jean has a lot hunger
'Jean is very hungry.' (Doetjes, 2008, 127)
b. Jean hat viel Hunger.
Jean has much hunger
'Jean is very hungry.'

Doetjes uses the label 'gradable verbs' for verbal degree gradation. Whereas French uses a different expression for degree gradation of verbs (beaucoup) than for grading the positive form of adjectives (très), German uses the same expression - sehr - in both contexts.
a. Il aime beaucoup cette langue.
he loves a lot this language
'He loves this language very much.'
b. Er liebt diese Sprache sehr.
he loves this language very
'He loves this language very much.'

In the fourth context, Doetjes lumps together several distinct subcontexts. The first subcontext is called 'eventive verbs' by Doetjes and represents what was called 'extent gradation' above. For this case (64), French uses beaucoup, whereas German makes use of viel rather than sehr. German shows a split in marking of verbal extent and degree gradation, whereas such a split does not show up in French. The second subcontext is gradation 
of predicatively used adjectives as in (65). Doetjes uses the term 'eventive adjectives' to denote this context. The reason is that in (65a) and (b) the degree expression specifies the frequency of Paul being ill. Doetjes' term 'eventive adjective' is dependent on the fact that beaucoup, and similarly viel in German, results in a frequency specification. In (65a) and (b) it is the frequency of Paul being ill that is indicated by the degree expression. Using très in (c) rather than beaucoup and sehr instead of viel leads to a degree reading specifying the intensity of Paul's illness.
a. Il va beaucoup au cinema.
'He goes to the movies a lot.'
b. Er geht viel ins Kino.
he goes much in.the cinema
'He goes to the movies a lot.'
(65) a. Paul est beaucoup malade.
Paul is a lot ill
'Paul is ill a lot.'
b. Paul ist viel krank.
Paul is much ill
'Paul is ill a lot.'
c. Paul est très malade.
Paul is very ill.
'Paul is very ill.'
d. Paul ist sehr krank.
Paul is very ill
'Paul is very ill.'

The third subcontext covers graded comparatives as in (66). For gradating comparatives both - French as well as German - use a different degree expression than for the positive form of adjectives. French uses beaucoup and German uses viel. This subcontext does not really fit with the other two subcontexts since in the other two cases the degree expression specifies the frequency of an event. In case of comparatives, the degree expression does not specify a frequency, but the difference that obtains between the two compared NPs. 

a. Paul est beaucoup plus grand que Daniel. Paul is a lot more tall than Daniel 'Paul is much taller than Daniel.'
b. Paul ist viel größer als Daniel. Paul is much taller than Daniel 'Paul is much taller than Daniel.'

The last two contexts distinguished by Doetjes are non-predicatively used mass (67) and count nouns (68). Neither French nor German has a distinction between mass and plural count quantity expressions similar to the English one between much and many. In French, adnominal quantity expressions require the partitive article $d e$. The partitive article is not required if the graded noun is used predicatively (62a). In German, viel agrees with its head noun in case and number and therefore inflection differs depending on whether the head noun is a mass noun, which is morphologically singular, or a plural count noun.
a. beaucoup de soupe
a lot of.the soup 'much soup'
b. viel Suppe
much soup
'much soup'
a. beaucoup de livres
a lot of.the books
'many books'
b. viele Bücher
much books
'many books'

Table 2 summarizes the distribution of high degree expressions in French and German. French uses très only with gradable adjectives and beaucoup in all other contexts. German makes use of sehr with gradable adjectives and for verbal degree gradation, whereas viel is used in all other contexts. Doetjes claims that degree expressions are only used in adjacent contexts, hence the distribution of German sehr and viel contradicts this assumption.

As table 2 shows, sehr is not found in adjacent contexts, but is restricted to contexts (i) and (iii). A solution for this problem would be to rearrange 


\begin{tabular}{|l|c|c|}
\hline Context of use & French & German \\
\hline (i) gradable adjectives & très & sehr \\
\hline (ii) gradable nominal predicates & \multirow{3}{*}{ beaucoup } & viel \\
\cline { 1 - 1 } (iii) gradable verbs & & sehr \\
\cline { 1 - 1 } (iv) eventive verbs, eventive adjectives, comparatives & & viel \\
\cline { 1 - 1 } (v) mass nouns & \\
\hline (vi) plural nouns & \\
\hline
\end{tabular}

Table 2: Degree expression continuum for French and German high degree expressions, based on Doetjes (2008).

the contexts but Doetjes argues that the order in contexts is a natural one based on the diachronic development of degree expressions. A further problem for Doetjes' degree expression continuum is provided by the distribution of the Persian degree expressions kheyli 'very' and ziad 'much.' Kheyli is used for degree gradation of adjectives (69a) as well as verbs (69b). Hence, kheyli is very much like German sehr, and ziad, which is used for extent gradation (70) and as an adnominal quantity expression (71), is much like German viel. The difference between the Persian and German degree expressions is that kheyli is also used with comparatives (72). Thus Doetjes' fourth context is split in Persian as ziad is used for extent gradation of verbs and adjectives but not for comparatives. This further indicates that this context consists of rather heterogeneous subtypes.

(69) Persian (Indo-Iranian < Indo-European)

a. Ou kheyli ghadboland ast.

3sG very tall is

' $\mathrm{S} /$ he is very tall.'

b. Oura kheyli dustdarad.

3sG.ACc very like.3sg

'S/he likes him/her very much.'

(70) Ou ziad knoonrizi dasht.

3sg much bleeding has

'S/he bled a lot.' (= extent)

(71) a. Dar daryache ab ziad ast.

in.the lake water much is

'There is a lot of water in the lake.' 
b. Ou ketabhaye ziadi darad.

3sg books much has

'S/he has many books.'

(72) In pesar kheyli bozorg-tar as dushash ast.

DEM boy very tall-COMP as his friend is

'The boy is much taller than his friend.'

The distribution of ziad and kheyli is summarized in table 3. Two contexts discussed for French and German are missing: gradable nominal predicates and eventive adjectives. Nevertheless, the distribution of degree expressions in Persian is problematic for Doetjes' continuum hypothesis.

Based on the German and Persian data, I reject Doetjes' continuum claim and go into a broader cross-linguistic comparison of the distribution of degree expressions in the next section. I will use different contexts to Doetjes and do not assume that they are naturally ordered in a degree expression continuum.

\begin{tabular}{|l|c|}
\hline \multicolumn{1}{|c|}{ Context of use } & Persian \\
\hline (i) gradable adjectives & kheyli \\
\hline (iii) gradable verbs & kheyli \\
\hline (iv.a) eventive verbs & ziad \\
\hline (iv.b) comparatives & kheyli \\
\hline (v) mass nouns & ziad \\
\hline (vi) count nouns & ziad \\
\hline
\end{tabular}

Table 3: Degree expression continuum for Persian.

\subsubsection{Cross-linguistic distribution of degree expressions}

As argued in section 2.1, there are two different subtypes of verb gradation, which are degree and extent gradation. Extent gradation can itself be subdivided into two subtypes: frequentative and durative extent gradation. Hence, we have to distinguish three different contexts for verb gradation, which yields five different strategies for marking these contexts. Table 4 summarizes these five different possibilities. The first option is that a language uses the same degree expression for all three contexts. As a general second option, a language could mark two contexts in the same way and 
employ a different degree expression for the third context. Either degree gradation could be marked differently from extent gradation or one of the subtypes of extent gradation could be marked in the same way as degree gradation, whereas the other one requires a different degree expression. The last option would be to mark all three contexts differently.

\begin{tabular}{|c|c|c|}
\hline degree gradation & extent gradation $_{\text {Frequency }}$ & extent gradation $_{\text {Duration }}$ \\
\hline A & $\bar{A}$ & $\mathrm{~A}$ \\
\hline A & $B$ & $\mathrm{~B}$ \\
\hline A & $\mathrm{A}$ & $B$ \\
\hline $\bar{A}$ & $\bar{B}$ & $\bar{A}$ \\
\hline $\mathrm{A}$ & $\mathrm{B}$ & $\mathrm{C}$ \\
\hline
\end{tabular}

Table 4: Possible distribution of adverbial degree expressions.

French uses the first option since beaucoup is uniformly used for degree as well as extent gradation. German on the other hand uses the second option: degree gradation is marked differently from extent gradation. Both subtypes of extent gradation are marked in the same way. Table 5 lists the distribution of adverbially used degree expressions in 27 languages, including French and German. The language sample is neither geographically nor genetically well balanced and only contains languages from Eurasia. Although the sample covers languages from different language families (Indo-European, Afro-Asiatic, Altaic, Kartvelian, Sino-Tibetian, FinnoUgric, Bantu), most of the languages belong to the Indo-European family. Therefore no valid typological generalizations can be proposed; nevertheless the data discussed in this section provide, as far as I know, the first large cross-linguistic comparison of the distribution of degree expressions. ${ }^{23}$

The languages in table 5 display only two of the possible strategies distinguished above. The languages either show the same distribution as French - option 1 - or they employ the strategy used in German, which was the second one. There is no language in the sample that uses one of the other three strategies. It could simply be chance that no other patterns have been attested by the data, probably due to the limited set of languages in

23 When I am speaking of the distribution of degree expressions, I am only concerned with the distribution of the neutrally high degree adverbials mentioned in the table. Different adverbials may have different distributions. 
the sample. Therefore, I do not claim that the other types cannot be found, they simply do not show up in my sample.

\begin{tabular}{|c|c|c|c|}
\hline \multirow[t]{2}{*}{ Language } & \multicolumn{3}{|c|}{ Verb gradation } \\
\hline & Degree gradation & $\begin{array}{c}\text { Extent gradation } \\
\text { (frequency) }\end{array}$ & $\begin{array}{c}\text { Extent gradation } \\
\text { (duration) }\end{array}$ \\
\hline German & sehr & viel & viel \\
\hline Dutch & erg/veel ${ }^{24}$ & veel & veel \\
\hline Russian & č̌en' & mnogo & mnogo \\
\hline Polish & bardzo & duzo & duzo \\
\hline Persian & kheyli & ziad & ziad \\
\hline Mandarin Chinese & hĕn & hěn dūo & hěn dūo \\
\hline Estonian & väga & palju & palju \\
\hline Tatar & $b i k$ & $k \ddot{u} p$ & $k \ddot{u} p$ \\
\hline Croation & jako & mnogo & mnogo \\
\hline Georgian & žalian & bevri & bevri \\
\hline Hebrew & me?od & harbe & harbe \\
\hline Japanese & totemo & takusan & takusan \\
\hline Korean & $a c w u$ & manhi & manhi \\
\hline French & beaucoup & beaucoup & beaucoup \\
\hline Romanian & mult & mult & mult \\
\hline Spanish & mucho & mucho & mucho \\
\hline Italian & molto & molto & molto \\
\hline Bulgarian & mnogo & mnogo & mnogo \\
\hline English $^{25}$ & (very) much, a lot & (very) much, a lot & (very) much, a lot \\
\hline Swedish & mycket & mycket & mycket \\
\hline Turkish & čok & čok & čok \\
\hline Finnish & paljon & paljon & paljon \\
\hline Khalka Mongolian & $i x$ & $i x$ & $i x$ \\
\hline Nepali & dherai & dherai & dherai \\
\hline Arabic & $k-\theta-r$ & $k-\theta-r$ & $k-\theta-r$ \\
\hline Swahili & sana & sana & sana \\
\hline Kikuyu & mons & mons & mons \\
\hline
\end{tabular}

Table 5: Cross-linguistic distribution of degree expressions used for verb gradation.

$\overline{24}$ Doetjes $(1997,2008)$ mentions that erg and veel are in complementary distribution, erg should only be used for degree gradation, whereas veel is restricted to extent gradation. But according to my information (both from the Nederlands and Belgium) veel can also be used as a degree modifier and sometimes is even preferred to erg.

25 See (Quirk et al., 1985, 469ff.) for a discussion of English intensifiers and GonzálesDíaz (2008) on a discussion of recent developments of English intensifiers. 
I will use the terms 'French-type' and 'German-type' to refer to the two attested types distinguished above. 'German-type' languages use different degree expressions for degree and extent gradation, whereas 'French-type' languages make use of the same expression for both. To refer to the expressions used for verb gradation, I introduce the notions ' $\mathrm{d}-$,' 'e-' and 'd/e' adverbials. 'd(egree)-adverbials' are adverbial degree expressions that are only used for degree gradation. 'e(xtent)-adverbials' are restricted to extent gradation, whereas 'd(egree)/e(xtent)-adverbials', like French beaucoup, can be used for degree as well as extent gradation. 'German-type' languages distinguish between 'd-' and 'e-adverbials,' whereas 'French-type' languages employ 'd/e-adverbials' for verb gradation. I take Swahili and Kikuyu as a special subtype of the 'French-type languages' as they differ in one important aspect from the other languages of this type. I call this special subtype 'Swahili-type languages.'

Starting with 'German-type' languages, table 6 shows the crosscategorical distribution of 'd-' and 'e-adverbials.' The table summarizes how these adverbials extend to the adjectival and nominal domain. For each domain, I only distinguish two subcontexts, which are (i) positive vs. comparative for adjectives and (ii) mass vs. count for nouns. Some of the contexts discussed by Doetjes, such as gradable nominals and eventive verbs, are not taken into consideration.

As indicated in the table, all the languages use the same expression for verbal degree gradation as well as intensifying the positive form of adjectives. The expression used for verbal extent gradation is always also used as an adnominal quantity expression. 'German-type' languages treat degree gradation, irrespective whether it is related to adjectives or verbs, in the same way. On the other hand, the expression of quantity, in the verbal as well as the nominal domain, is also treated in the same way. All of these languages, except Persian and Japanese, use the expression used for extent gradation also for grading comparatives. Comparatives seem to be the only context that shows variance in marking, whereas all the languages are uniform with regard to the other gradation contexts. 
2 Gradation and degree expressions

\begin{tabular}{|c|c|c|c|c|c|}
\hline \multirow[t]{2}{*}{ Language } & \multicolumn{2}{|c|}{ Adjectival domain } & \multicolumn{2}{|c|}{ Nominal domain } & \multirow{2}{*}{$\begin{array}{l}\text { Verbal } \\
\text { domain }\end{array}$} \\
\hline & Positive & Comparative & Mass & Count & \\
\hline German & sehr & viel & viel & viel & sehr $_{D} /$ viel $_{E}$ \\
\hline Russian & očen' & mnogo & mnogo & mnogo & $\begin{array}{l}\text { očen }_{D} / \\
\text { mnogo }_{E}\end{array}$ \\
\hline Dutch & erg & veel & veel & veel & $\operatorname{erg}_{D} / \operatorname{veel}_{(D) E}$ \\
\hline Polish & bardzo & duzo & duzo & duzo & bardzo $o_{D} / d u z o_{E}$ \\
\hline $\begin{array}{l}\text { Mandarin } \\
\text { Chinese }\end{array}$ & hěn & hěn duō & hěn duō & hěn duō & $\begin{array}{l}\text { hěn }{ }_{D} / \text { hěn } \\
d u \bar{o}_{E}\end{array}$ \\
\hline Tatar & $b i k$ & $k \ddot{u p}$ & $k \ddot{u p}$ & $k \ddot{u} p$ & $b i k_{D} / k \ddot{u} p_{E}$ \\
\hline Croatian & jako & mnogo & mnogo & mnogo & $\begin{array}{l}\text { jako }_{D} / \\
\text { mnogo }_{E}\end{array}$ \\
\hline Georgian & žaljan & bevri & bevri & bevri & $\begin{array}{l}\text { žaljan }_{D} / \\
\text { bevri }_{E}\end{array}$ \\
\hline Estonian & $v \ddot{g} g a$ & palju & palju & palju & $\begin{array}{l}\text { väga } a_{D} / \\
\text { palju }_{E}\end{array}$ \\
\hline Korean & $a c w u^{26}$ & manhi & manhi & manhi & $\begin{array}{l}\operatorname{acwu}_{D} / \\
\operatorname{manhi}_{E}\end{array}$ \\
\hline Hebrew & me?od & harbe & harbe & harbe & $\begin{array}{l}\operatorname{me} \operatorname{od}_{D} / \\
\text { harbe }_{E}\end{array}$ \\
\hline Persian & kheyli & kheyli & ziad & ziad & $\begin{array}{l}\text { kheyli }_{D} / \\
\text { ziad }_{E}\end{array}$ \\
\hline Japanese & totemo & totemo & takusan & takusan & $\begin{array}{l}\text { totemo }_{D} / \\
\text { takusan }_{E}\end{array}$ \\
\hline
\end{tabular}

Table 6: Cross-categorical distribution of 'd'- and 'e'-adverbials.

The cross-categorical distribution of ' $d$ /e-adverbials' is summarized for 'French-type' languages in table 7. As shown in the table, 'French-type' languages differ with regard to the marking of the positive form of adjectives. Either the verbal degree expression extends to all contexts, including the positive form, like Bulgarian or Italian, or different degree expressions are required for the positive form of adjectives as in French and Spanish. Further variance exists with regard to the mass/count distinction. Most languages use the same quantity expression for mass and count

Whether there is a distinct class of adjectives in Korean is highly disputed and I do not want to take a stance on that issue. 
nouns; only English and Khalka Mongolian show a split in marking of both types of nouns. In both languages, the quantity expression used with mass nouns has a broader distribution than the one used with count nouns. But it should be noted that in English the split between mass and count only shows up with much and many but not with a lot, which can be used with mass and count nouns alike. Hence, the mass/count distinction does not extend throughout the whole system of nominal quantity expressions in English but only holds for particular lexical items.

\begin{tabular}{|c|c|c|c|c|c|}
\hline \multirow[t]{2}{*}{ Language } & \multicolumn{2}{|c|}{ Adjectival domain } & \multicolumn{2}{|c|}{ Nominal domain } & \multirow{2}{*}{$\begin{array}{l}\text { Verbal do- } \\
\text { main }\end{array}$} \\
\hline & Positive & Comparative & Mass & Count & \\
\hline French & trés & beaucoup & $\begin{array}{l}\text { beau- } \\
\text { coup }\end{array}$ & beaucoup & $\begin{array}{l}\text { beau- } \\
\operatorname{coup}_{D / E}\end{array}$ \\
\hline Spanish & muy & mucho & mucho & mucho & mucho $_{D / E}$ \\
\hline Romanian & foarte & mult & mult & mult & mult $_{D / E}$ \\
\hline English & very & much, a lot & $\begin{array}{l}\text { much, } \\
\text { a lot }\end{array}$ & $\begin{array}{l}\text { much, } \\
\text { a lot }\end{array}$ & $\begin{array}{l}\text { much, } \\
\text { a } \operatorname{lot}_{D / E}\end{array}$ \\
\hline Finnish & hyvin & paljon & paljon & paljon & paljon $_{D / E}$ \\
\hline Bulgarian & mnogo & mnogo & mnogo & mnogo & $m n o g o_{D / E}$ \\
\hline Italian & molto & molto & molto & molto & molto $_{D / E}$ \\
\hline Swedish & mycket & mycket & mycket & mycket & mycket $_{D / E}$ \\
\hline Turkish & $\check{c ̌ o k}$ & čok & čok & čok & $\check{c} o k_{D / E}$ \\
\hline $\begin{array}{l}\text { Khalka } \\
\text { Mongolian }\end{array}$ & $i x$ & $i x$ & $i x$ & olon & $i x_{D / E}$ \\
\hline Nepali & dherai & dherai & dherai & dherai & dherai $_{D / E}$ \\
\hline Arabic & dzidd & $k-\theta-r$ & $k-\theta-r$ & $k-\theta-r$ & $k-\theta-r_{D / E}$ \\
\hline
\end{tabular}

Table 7: Cross-categorical distribution of ' $\mathrm{d} / \mathrm{e}$ '-adverbials.

The following tentative generalizations can be derived from the data in the tables shown above:

(73) (i.) If a language uses different adverbials for extent and degree gradation ('d-' vs. 'e-adverbials'), the expression that is used for verbal degree gradation ('d-adverbial') is also used for in- 
tensifying the positive form of adjectives. ${ }^{27}$

(ii.) If a language uses different adverbials for extent and degree gradation ('d-' vs. 'e-adverbials'), the expression that is used for extent gradation ('e-adverbial') is also used in the nominal domain.

(iii.) If a language uses the same adverbial for extent and degree gradation ('d/e-adverbial'), the expression used as ' $\mathrm{d} / \mathrm{e}$ adverbial' extends - at least - to the nominal domain and to comparatives.

(73ii) and (iii) allow for the generalization in (74):

(74) (iv) Expressions used for extent gradation of verbs are also used in the nominal domain, irrespective whether the language distinguishes between 'd-' and 'e-adverbials' or not.

A short note on the nominal mass/count distinction is appropriate. Doetjes $(2012$, 2565) mentions that adnominal quantity expressions in English can be extended to adverbial uses, i.e., they function as an expression of extent gradation. Either these adnominal expressions are insensitive to the mass/count distinction as, for example, a lot or if they are sensitive to this distinction, as in the case of much and many, the expression used with mass nouns is used in the adverbial context too. This observation is also confirmed by the Khalka Mongolian data mentioned above.

Two classes of languages contradict - at least some - of the generalizations made above. The first class, just presenting an apparent contradiction, is Tagalog. The second class, presenting a real contradiction, is formed by the 'Swahili-type' languages. Tagalog uses different grading devices for different lexical categories. In (75) it is shown how the positive form of an adjective is graded and intensification of a comparative form is shown in (76). The positive form takes the prefix napaka-, which indicates a high degree. There is no corresponding way to intensify comparatives; rather an element meaning truly has to be used, which is ambiguous between indicating a high degree and an epistemic reading expressing certainty.

This claim is supported by Muroi (2010) who shows, based on a corpus study, that in German the positive and the comparative form of adjectives mostly take different degree expression. 




(76) Talaga-ng mas ma-tangkad ang bata sa kaniya-ng kapatid. true-LNK COMP ADJ-tall SUB child DAT 3GEN-LNK sibling 'The boy is much taller than his brother.'

A high quantity with regard to nouns is expressed by an adjective meaning plenty (77). The affix napaka- cannot be used with nouns but is restricted to adjectives. As the example shows, there is no mass/count distinction that is reflected in the choice of the adnominal quantity expression.

$$
\begin{aligned}
& \text { Kumain siya ng ma-rami-ng saping/sopas. } \\
& \text { eat<PST.AV> 3sG.SUB NSUB ADJ-plenty-LNK banana/soup } \\
& \text { 'He ate many bananas/soup.' }
\end{aligned}
$$

There are two different ways of expressing verbal degree gradation. Either the same construction as used for comparatives can be used (78), or a degree expression which is uniquely linked to the predicate by the linker (na)ng can be employed (79). Husto also expresses a high degree but is restricted to adverbial contexts and therefore can neither used with adjectives nor nouns.

$$
\begin{aligned}
& \text { Talaga-ng ginulat } n g \quad \text { leon ang bata. } \\
& \text { true-LNK frighten<PST.UV > NSUB lion SUB child }
\end{aligned}
$$$$
\text { 'The lion frightened the child a lot.' }
$$

$$
\begin{aligned}
& \text { Ginulat ng leon (na)ng husto ang bata. } \\
& \text { frighten<PST.UV> NSUB lion LNK INTS SUB child } \\
& \text { 'The lion frightened the child a lot.' }
\end{aligned}
$$

The examples in (80) and (81) illustrate that (na)ng husto is also used for extent gradation. In (80) this is illustrated for the durative subtype and in (81) for the frequentative one. Talaga-ng cannot be used for expressing extent gradation rather with the verbs for sleep and go only an epistemic interpretation is possible.

(80) Na-tulog (na)-ng husto ang bata kagabi.

PST.UV-sleep LNK INTS sUB child last.night

'The boy slept a lot last night.' 


$$
\begin{aligned}
& \begin{array}{l}
\text { Pumunta siya sa sine-han (na)-ng husto. } \\
\text { go<PST.UV> }
\end{array} \text { 3SG.SUB DAT movie-LOC LNK INTS }
\end{aligned}
$$

'He went to the cinema a lot.'

In Tagalog, degree expressions do not extend across lexical categories, taking constructions as shown in (76) and (77) aside, which make use of lexical items that are functionally not restricted to the expression of gradation. This seems only to hold for native degree expressions, since sobra 'too much,' which is a loan from Spanish, can be used with adjectives, verbs as well as nouns. The case of grading the positive form of adjectival concepts (75) is not a counterexample as gradation is morphologically and not syntactically expressed and therefore is not covered by the generalizations made above.

The 'Swahili-type' languages Swahili and Kikuyu show the distribution of degree expressions as summarized in table $8 .^{28}$ The relevant deviation concerns the nominal domain; unlike 'German-type' and 'French-type' languages, 'Swahili-type' languages do not use the expression used for extent gradation in nominal domain too. Instead, Swahili sana is restricted to the adjectival and verbal domain, whereas -ingi is used with mass and count nouns. Kikuyu is special in having a distinct form for grading comparatives which is not used in the other contexts.

\begin{tabular}{|l|l|l|l|l|l|}
\hline Language & \multicolumn{2}{|c|}{ Adjectival domain } & \multicolumn{2}{l|}{ Nominal domain } & $\begin{array}{l}\text { Verbal } \\
\text { domain }\end{array}$ \\
\cline { 2 - 5 } & Positive & Comparative & Mass & Count & \\
\hline Swahili & sana & sana & -ingi & -ingi & sana $_{D} / E$ \\
\hline Kikuyu & monэ & makeria & -inge & -inge & mon ${ }_{D} / E$ \\
\hline
\end{tabular}

Table 8: Cross-categorical distribution of degree expressions in 'Swahilitype' languages.

The 'Swahili-type' languages contradict the generalization expressed in (73), namely that languages with 'd/e-adverbials' use this expression also in the nominal domain and with comparatives. Hence, the generalizations

$\overline{28}$ See Krifka \& Zerbian (2008) for a broader discussion of quantity expressions and quantifiers across Bantu languages. 
made above are restricted to 'German-type' and 'French-type' languages and do not hold for 'Swahili-type' languages.

The generalizations for 'German-type' and 'French-type' languages give rise to a couple of questions: first, is there any particular reason why degree expressions used for extent gradation (German viel, French beaucoup) are also used as adnominal quantity expressions and those restricted to degree gradation (German sehr and French très) are not? Second, does German display a difference between extent and degree gradation that does not overtly exist in French as such? Or does French display the same distinction as German does but masked by using the same degree expression? In chapter 4, I will argue that 'German-' as well as 'French-type' languages show the same distinction between extent and degree gradation. I will argue that extent and degree gradation are realized in two different syntactic configurations, irrespective whether a language distinguishes between ' $d-$ ' and 'e-adverbials' as in German, or if it does not, as is the case with French. This syntactic difference will also provide a natural explanation to the first question. I will argue that quantity is expressed in the same kind of syntactic configuration irrespective whether it is in the nominal or verbal domain.

A further question is why, in all languages that obey the above generalizations (except Persian and Japanese), comparatives are graded with expressions that are not restricted to degree contexts. In 'French-type' languages comparatives pattern with all other contexts, whereas in 'Germantype' languages they are graded by using extent/quantity expressions. An answer to this question is beyond the limits of the thesis.

At last, it is surely a question whether more languages obey the generalizations made above than contradict them like the 'Swahili-type' languages do. A broader cross-linguistic comparison could reveal more strategies for expressing gradation across categories, and this would require a principal explanation for why these differences arise.

\subsection{Conclusion}

In the first section, the notion of gradation was defined as a linguistic process of comparing degrees. Degrees represent measurement values of a scale; hence, gradation is best analyzed with regard to scales. A second essential element of gradation is degree expressions, which introduce the 
degree of comparison. In a broad sense, the notion of a 'degree expression' covers all devices used for gradation ranging from comparative degree morphology to degree expressions such as German sehr.

Verb gradation shows an additional complexity not shared with adjectival or nominal gradation. If verbs are eventive, gradation can either affect a gradable property related to the verb or a gradable property of the respective event. This results in a distinction between degree and extent gradation. Two basic types of languages have been identified with regard to the expression of verb gradation. 'German-type' languages use different degree expressions for extent and degree gradation, whereas 'French-type' languages use the same expression for both. It was shown that expressions used for extent gradation, in 'German-' as well as 'French-type' languages, are also always used in the nominal domain as adnominal quantity expressions. It was argued that neither extent gradation nor the specification of an adnominal quantity requires a quantificational analysis. A quantificational analysis was uniformly rejected for all degree expressions. Nevertheless, the specification of the exact mode of semantic composition, i.e., modification vs. argument saturation, is postponed until chapter 5 . 